\title{
Definição de uma faixa pluviométrica crítica para deflagração de movimentos de terra em taludes rodoviários localizados no trecho da serra do mar da rodovia BR-376/PR
}

\author{
Mariana M. Victorino ${ }^{1}$, Liamara Paglia Sestrem² e Alessander C. M. Kormann³
}

\begin{abstract}
Resumo: Este artigo apresenta a metodologia empregada para a definição de uma faixa pluviométrica crítica para deflagração de escorregamentos de terra nos taludes rodoviários da rodovia BR-376, no trecho da Serra do Mar Paranaense. A construção do modelo proposto partiu do entendimento e compilação da intensidade e duração tanto de eventos pluviométricos que resultaram em processos instabilizantes na região como daqueles que historicamente não deflagraram danos às encostas. A relação entre pluviometria e ocorrência de escorregamentos proposta representa uma importante ferramenta para criação sistemas de alerta e desenvolvimento de um plano de mitigação de movimentos de terra para o local. Sua aplicação torna-se mais eficiente se associada à estações pluviométricas capazes de processar dados em tempo real, possibilitando assim a emissão de alertas com o objetivo de se tomar decisões em termos de mobilização de equipes, interrupção ou desvio preventivo do tráfego ou controle de velocidade.
\end{abstract}

Palavras-chave: escorregamentos de terra, Serra do Mar, Limiar pluviométrico.

\begin{abstract}
This paper describes the methodology employed to define a critical rainfall range that could potentially trigger landslides in slopes located at the margin of the highway BR-376, at Serra do Mar in Parana State, Brazil. The development of the proposed model started from the understanding and analysis of the intensity and the duration of rainfall events that resulted in destabilizing processes in the region. The rainfalls that historically did not trigger any damage to the slopes were also taken into account. The study proposes a relationship between rainfall and the occurrence of landslides, which represents an important tool for creating warning systems and development of specific plans to mitigate land movement. The application becomes even more efficient if associated with real-time rainfall measurement, thus enabling the issuing of alerts for decisionmaking in terms of teams mobilization, interruption or preventive traffic deviation and speed control.
\end{abstract}

Keywords: landslides, Serra do Mar, Rainfall threshold.

\section{INTRODUÇÃO}

A ocorrência de deslizamentos de terra decorrentes de eventos pluviométricos de grande intensidade ao longo de todo o território nacional nos últimos anos (e.g. Santa Catarina - Nov/2008, Angra dos Reis - Jan/2010, Nova Friburgo - Jan/2011, Litoral do Paraná - Mar/2011, BR376 - Mar/2011) tem resultado em significativas perdas humanas e materiais. Em particular, o trecho da BR-376 situado na Serra do Mar entre Curitiba (PR) e Garuva (SC) possui um histórico de eventos de instabilização caracterizados tanto por processos lentos como por episódios mais críticos decorrentes de precipitações pluviométricas de grande duração e intensidade (Kormann et al, 2013).

Os maciços naturais situados nessa região envolvem solos residuais e depósitos coluvionares com padrões estruturais variados. À medida que as rodovias estão implantadas nesse ambiente naturalmente sujeito a fenômenos de instabilização, o estudo de metodologias que identifiquem cor-

\footnotetext{
1 Mariana M. Victorino, Departamento de Construção Civil - Programa de Pós-Graduação em Engenharia de Construção Civil, UFPR. (mari_meza@hotmail.com)

2 Liamara Paglia Sestrem, Departamento de Construção Civil - Programa de Pós-Graduação em Engenharia de Construção Civil, UFPR.

(liamarasestrem@gmail.com)

3 Alessander C. M. Kormann3, Departamento de Construção Civil

- Programa de Pós-Graduação em Engenharia de Construção Civil, UFPR. (alessander@ufpr.br)
}

Manuscrito recebido em 17/11/2015 e aprovado para publicação em $16 / 02 / 2017$

Este artigo é parte de TRANSPORTES v. 25, n. 1, 2017. ISSN: 2237-1346 (online). DOI:10.14295/transportes.v25i1.1038 relações entre as condições de segurança de taludes rodoviários e eventos pluviométricos com diferentes durações e intensidades assume particular importância em termos de gestão da segurança rodoviária.

Estudos direcionados ao tema propõem a definição de limiares pluviométricos deflagradores de movimento de massa baseados em modelos de processos físicos ou empíricos (e.g. Tatizana et al.,1987b; Kanji et al,1997; Yuan et al.,2005; Guzzetti et al.,2007, Peruccacci et al. 2012 e D’Orzi, 2011, Victorino, 2015). As metodologias baseadas em processos físicos avaliam o nível de suscetibilidade de encostas considerando os processos de infiltração da chuva e informações como: condições geoestruturais, litológicas, topográficas, hidrogeológicas, entre outras. A qualidade dos resultados está fortemente relacionada à quantidade e qualidade dos dados disponíveis para alimentação do modelo.

Os limiares pluviométricos determinados por meio de modelos empíricos baseiam-se geralmente em eventos reais de chuva e nos movimentos de massa diretamente relacionados. Os limiares são usualmente definidos empiricamente a partir de uma "nuvem" de pontos que representam as condições pluviométricas (precipitação acumulada, intensidade pluviométrica, duração do evento, etc.) registradas em cada uma das ocorrências de escorregamentos. Limiares empíricos para o início de movimentos de massa podem ser definidos em caráter global, regional ou local. Exemplos de aplicação dessa metodologia podem ser encontrados nos estudos apresentados por Tatizana et al. (1987a, b), Kanji et al (1997), Yuan et al.(2005), Guzzetti et al. (2007), Peruccacci et al. (2012), D’Orzi (2011) e Saito et al. (2010).

Tatizana et al. (1987a, b) verificou a influência direta de pelo menos 6 fatores na deflagração de escorregamentos 


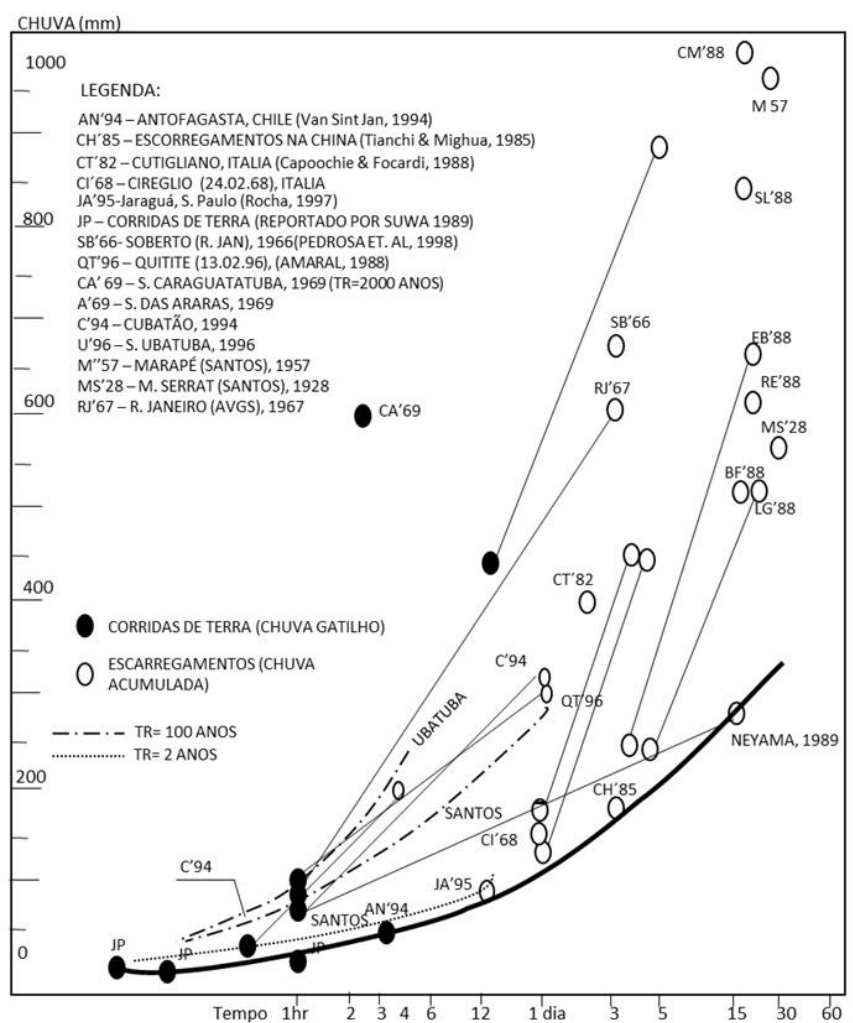

Figura 1. Relação entre chuva acumulada para diversos movimentos de terra e critério de chuva deflagradora de corridas e escorregamentos Fonte: Adaptado de Kanji et al, 1997

na Serra do Mar: geologia, geomorfologia, declividade, cobertura vegetal, regime pluviométrico e posição da encosta. Contudo, perante a dificuldade de considerá-los isoladamente no estudo, os autores optaram por analisar o comportamento das ocorrências de chuva por setores. Para a região de Cubatão (SP), chuvas com e sem registros de escorregamentos auxiliaram os autores na definição dos limiares pluviométricos empíricos baseados na pluviometria acumulada em 96 horas e na intensidade pluviométrica em 1 hora, sendo possível assim determinar parâmetros ("K") específicos para cada modelo de ruptura. $\mathrm{O}$ estudo mostra a importância de uma relação entre a precipitação acumulada antecedente e a intensidade horária na deflagração dos escorregamentos. Os autores ressaltam ainda que a aplicação do modelo para as outras porções da serra, que não as próximas à Refinaria Presidente Bernandes (setor de estudo), deve incorporar as diferenças nas condições geotécnicas.

Kanji et al. (1997) discutem os principais fatores que causam corridas de terra (chuva, geologia e declividade) e sua distinção com relação a escorregamentos. Baseado na correlação entre a intensidade de chuva e a ocorrência de movimentos de massa em diferentes regiões do mundo, os autores propuseram um limiar volume $\times$ duração associado à deflagração de movimentos (Figura 1).

No gráfico proposto por Kanji et al. (1997) a precipitação é apresentada em termos acumulados. Ou seja, quando os pontos correspondentes a um movimento de massa estão ligados entre si, as chuvas de curta duração estão contidas no evento pluviométrico de maior duração que deflagrou o movimento. $\mathrm{O}$ estudo apresenta curvas estatísticas para as chuvas com período de recorrência de 2 e 100 anos de cidades próximas à cidade de Cubatão. Comparando essas curvas com as chuvas acumuladas que deflagraram corridas e escorregamentos em 1994 na cidade de
Cubatão, verifica-se que o tal evento esteve associado a 100 anos de período de recorrência.

A curva traçada imediatamente abaixo dos movimentos de massa analisados pelos autores, Equação (1) é caracterizada por uma relação direta entre intensidade e duração da chuva, representando a condição mínima para ocorrência de deslizamentos e corridas em caráter global.

$$
\mathrm{P}=21,1(\mathrm{t})^{0,48}
$$

Verifica-se que em geral os escorregamentos tendem a ocorrer para altos valores de precipitação acumulados (mais de 12 horas), enquanto as corridas ocorrrem com eventos de grande intensidade em um curto período de tempo. Kanji et al. (1997) também apresentaram uma comparação entre o limiar pluviométrico proposto com outros publicados na literatura, sendo possível concluir que a curva proposta pelos autores tende a ser mais conservadora.

Assim, é com base nessa metodologia que nos itens subsequentes se apresenta o procedimento utilizado para definição de uma faixa pluviométrica crítica no trecho de 34 quilômetros de extensão da BR-376 situado na Serra do Mar Paranaense, entre os municípios de São José dos Pinhais (PR) e Garuva (SC).

\section{CARACTERIZAÇÃO DA ÁREA DE ESTUDO}

A Serra do Mar brasileira caracteriza-se por um relevo montanhoso originado através de processos geológicos e geomorfológicos diversos. Sua formação está inserida no compartimento das Serras e Morros e localizada na região costeira do país, mais especificamente entre os estados do Rio de Janeiro e o norte de Santa Catarina. Possui uma extensão aproximada de $2.000 \mathrm{~km}$, largura de 5 a $10 \mathrm{~km}$ e altitude média de $1.000 \mathrm{~m}$. 


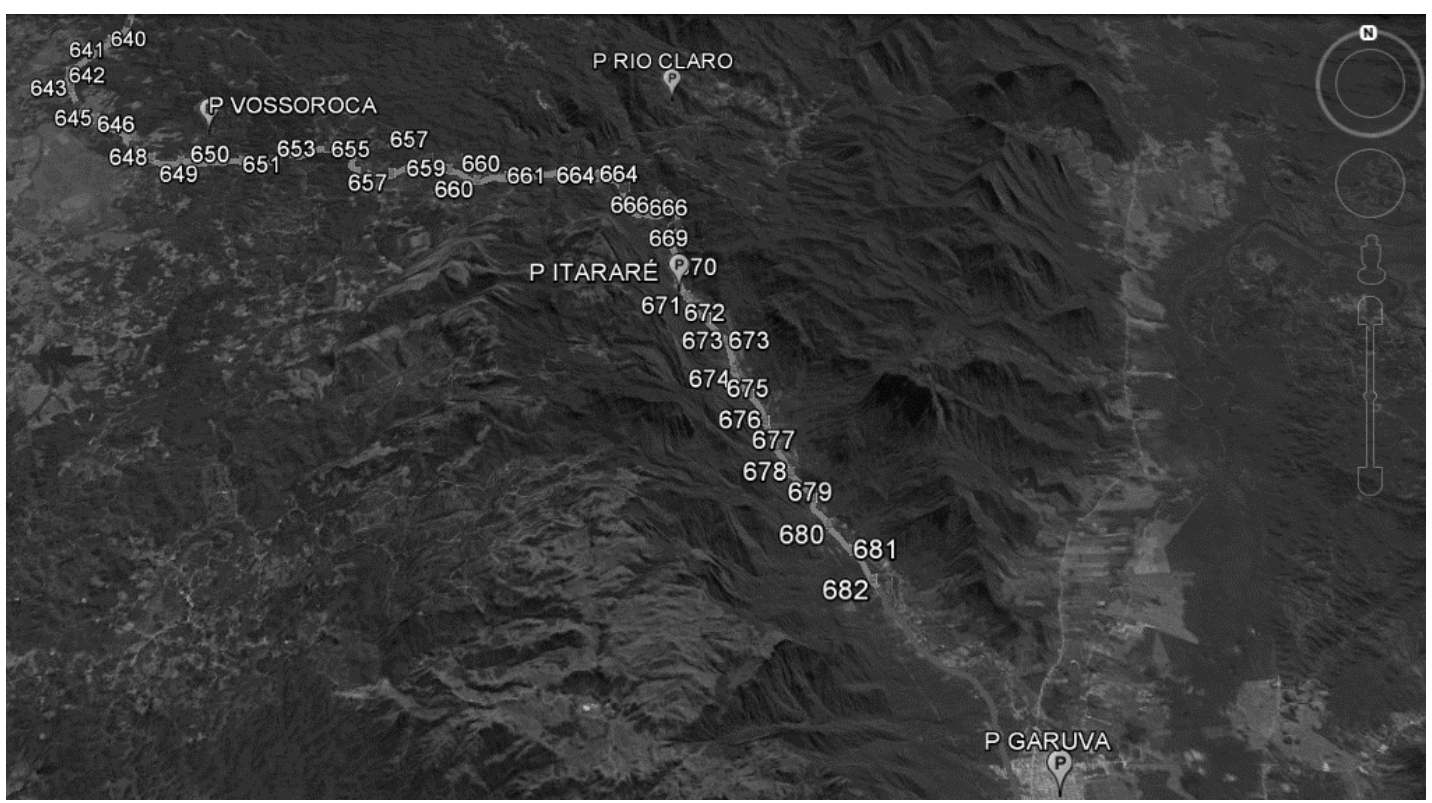

Figura 2. Localização dos pluviógrafos em operação próximos a área de estudo

Fonte: Modificado de VICTORINO et al., 2015

A área de estudo compreende o trecho entre os quilômetros 648 e 682 da BR-376 inserido na Serra do Mar Paranaense. O local caracteriza-se por um relevo fortemente ondulado e composto principalmente por solos coluvionares e residuais provenientes de formações de granito, migmatito e gnaisse.

Destaca-se ainda a ocorrência de escarpas íngremes terrosas, rochosas ou mistas, que após serem submetidas às intervenções necessárias à implantação da rodovia caracterizam-se por uma grande quantidade de taludes em corte e em aterro que tornam o local suscetível a problemas geotécnicos em geral, especialmente os relacionados à estabilidade de taludes (Mezzomo et al., 2012).

O clima local classifica-se como tropical úmido, sem uma estação seca, sendo a temperatura média do mês mais quente superior a $18^{\circ} \mathrm{C}$. A região é influenciada ainda pelos sistemas atlânticos polares e tropicais e não apresenta uma uniformidade climática em toda a sua área, devido aos fatores geográficos que acentuam determinadas características das massas de ar lá atuantes (ITCF, 1987). Em padrões normais a região apresenta isoietas médias na faixa de 2.400 a $2.500 \mathrm{~mm} / \mathrm{ano}$ entretanto a presença de montanhas traz complexidade para o escoamento atmosférico e causa fenômenos como chuvas orográficas, movimento de ar ascendente localizado e forçado, bloqueio de frentes frias ou quentes, ondas de montanha, turbulência devido à quebra destas ondas, etc. Estes fenômenos dificultam a previsão da precipitação próxima a regiões serranas (INPE, 2013).

\section{LIMIAR PLUVIOMÉTRICO PARA DEFLA- GRAÇÃO DE ESCORREGAMENTOS NA ÁREA DE ESTUDO}

O desenvolvimento do limiar pluviométrico para deflagração de escorregamentos foi dividido em três etapas principais: levantamento de dados históricos e informações pertinentes à área de estudo, análises, seleção e agrupamento das informações obtidas, e, por fim, elaboração do diagrama de correlação com a definição da faixa crítica de chuva para deflagração de escorregamentos onde o limite inferior da faixa representa a condição mínima para ocorrência de deslizamentos.

\subsection{Histórico de chuva e movimentos de massa na área de estudo}

De acordo com as informações obtidas em projetos, registros e fotos cedidos pela concessionária responsável pela concessão desse trecho da rodovia, o histórico de instabilização de taludes entre janeiro de 2008 e março de 2014 na área de estudo caracterizou-se por:

- 37 escorregamentos em taludes de terra entre os dias 20 e 30 de novembro de 2008 ;

- 35 escorregamentos em taludes de terra entre os dias 11 de março de 2011 e 13 de março de 2011;

- 13 escorregamentos isolados em taludes de terra entre janeiro de 2008 e agosto de 2014.

A seleção da estação pluviométrica adotada no presente estudo partiu do levantamento das estações pluviométricas existentes próximas à área de interesse. Foram avaliados registros de quatro diferentes pluviógrafos, denominados P Rio Claro, P Vossoroca, P Itararé e P Garuva (Figura 2).

Verificou-se que somente o pluviógrafo de Garuva esteve em operação durante todo período no qual os escorregamentos registrados na rodovia ocorreram.

Também foi verificado que existe uma diferença significativa entre os volumes de chuva registrados nos diferentes instrumentos num dado momento.

Com relação aos eventos que resultaram em escorregamentos na área de estudo, ressalta-se:

- As precipitações acumuladas registradas no pluviógrafo Garuva, instalado ao sul da rodovia, tendem a ser mais volumosas. Apesar disso, o evento pluviométrico registrado em março de 2011 mostrou-se uma exceção à essa característica, quando o pluviógrafo Itararé, localizado na porção central da rodovia, registrou as maiores precipitações, seguido do de Rio Claro, localizado mais ao norte;

- O grande volume de chuvas registrado pelo pluviógrafo Itararé, principalmente no dia 11 de março de 2011, pode justificar a concentração dos escorregamentos nas imediações do mesmo; 


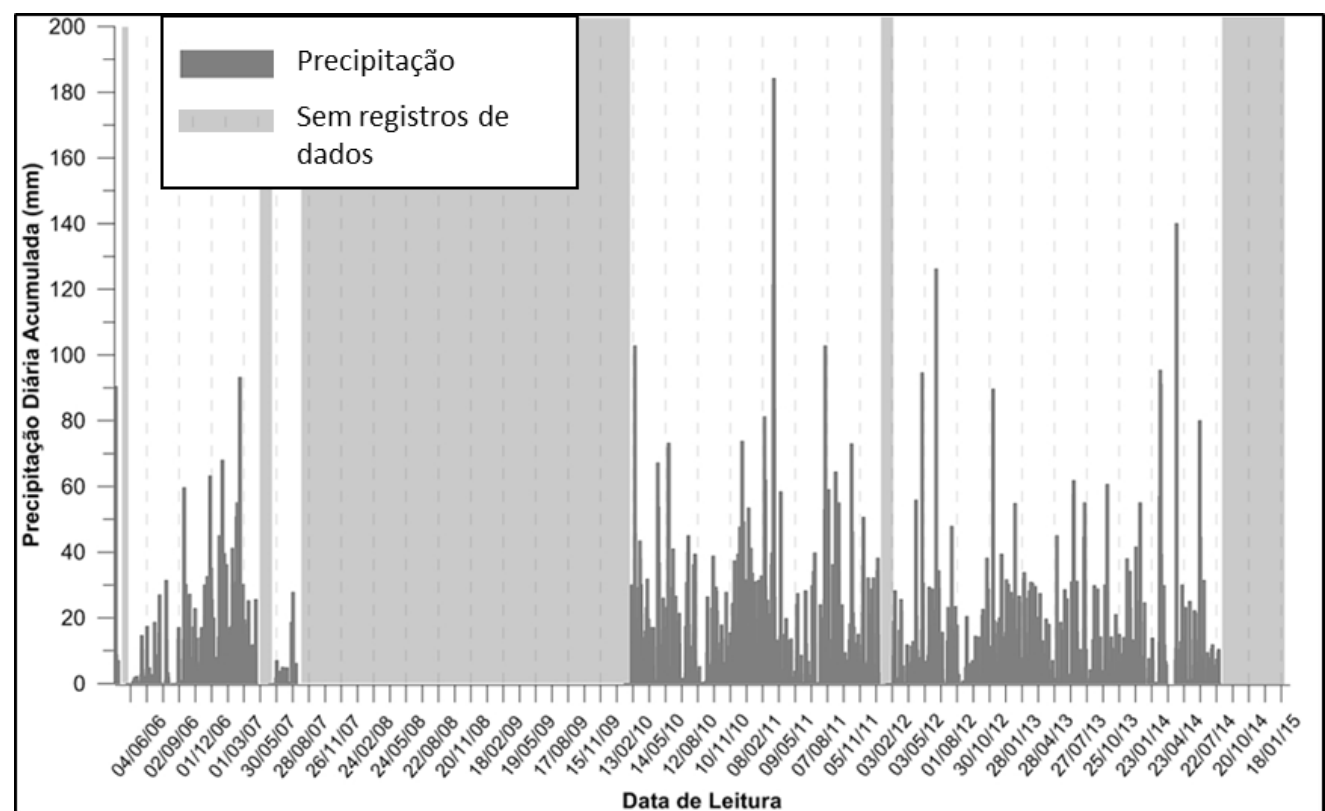

Figura 3. Precipitação diária acumulada registrada no posto de monitoramento Itararé - Em destaque períodos sem registros de dados

- Em 2008, o volume de chuva registrado pelo pluviógrafo Garuva também foi muito maior que os demais, justificando assim os escorregamentos localizados na porção sul da rodovia naquele ano. Cabe salientar ainda que provavelmente ocorreram outros eventos intensos nas demais regiões da rodovia pois, nesta ocasião, os deslizamentos ficaram distribuídos ao longo de todo o trecho em concessão;

- Em 22 de janeiro de 2010 foram registrados 3 escorregamentos nos km 616+700,654+550 e 657+380. A distância entre o pluviógrafo de Garuva (instrumento mais próximo) e esses taludes foi um limitador a associação da chuva registrada aos escorregamentos. $\mathrm{O}$ mesmo conceito foi aplicado ao escorregamento de 22 de fevereiro de 2010 no km 657+700;

- Verifica-se ainda que os pluviógrafos Rio Claro e Vossoroca tendem a registrar menores volumes de chuva, estando normalmente abaixo daquelas historicamente registradas em Itararé.

As diferenças observadas entre os volumes de chuva registrados em cada estação podem ser associadas às diferentes altitudes nas quais os equipamentos estão instalados e consequentemente à variabilidade espacial das chuvas como consequência do relevo fortemente acidentado. Com base nesse contexto, concluiu-se que o pluviógrafo denominado Itararé possui dados mais representativos para a área de estudo. Tal escolha considerou ainda o fato desse equipamento estar localizado às margens da rodovia BR-376, no km 670+800 m, estando posicionado a no máximo $17 \mathrm{~km}$ do ponto mais extremo da área de interesse. Trata-se de um pluviógrafo do tipo caçamba basculante, cuja captação e armazenamento de dados é feita de modo automatizado. Os registros de chuva utilizados neste estudo compreenderam um período entre os dias 08 de março de 2006 e 01 de agosto de 2014 (Figura 3).

O pluviógrafo não armazenou dados durante os seguintes períodos: 18/03/2006 a 10/04/2006, 04/08/2006 a $12 / 08 / 2006, \quad 05 / 04 / 2007$ a 11/05/2007, 22/07/2007 a $22 / 01 / 2010,28 / 12 / 2011$ a 19/01/2012, 05/01/2014 a $14 / 01 / 2014,08 / 03 / 2014$ a $12 / 03 / 2014$.

\subsection{Organização e tratamento dos dados históricos}

Como parte da etapa de organização da série histórica de registros de precipitação, foi preciso definir uma condição para delimitar todos os eventos pluviométricos. Tais ocorrências tiveram seus limites temporais associados às datas e aos horários do início e do final da precipitação. Como o equipamento responsável pelos registros tem frequência de leituras diária, definiu-se como término do evento a ocorrência de um período de 24 horas ( 1 dia) sem precipitação. Os registros de chuva foram então agrupados em eventos pluviométricos com 24, 48, 72, 96, 120, 144, 168 e acima de 192 horas de duração, totalizando 1317 eventos. A Tabela 1 apresenta um resumo com a quantidade de cada evento pluviométrico captado pela estação Itararé e adotados neste estudo.

Tabela 1. Número de eventos registrados pela estação Itararé conforme sua duração

\begin{tabular}{cc}
\hline Eventos pluviométricos & Número total \\
\hline 24 horas de duração & 248 \\
48 horas de duração & 201 \\
72 horas de duração & 154 \\
96 horas de duração & 120 \\
120 horas de duração & 100 \\
144 horas de duração & 82 \\
168 horas de duração & 67 \\
192 horas ou mais de duração & 345 \\
Total de eventos pluviométricos & 1317 \\
\hline
\end{tabular}

Na sequência, os 1317 eventos pluviométricos foram separados em dois grupos: o primeiro compreendeu os registros de chuva que estavam associados a movimentos de terra e o segundo aqueles que não resultaram em processos instabilizantes. $\mathrm{O}$ procedimento consistiu ainda em avaliar se os escorregamentos registrados estavam relacionados com os eventos pluviométricos correspondentes e excluir do banco de dados aqueles que não tiveram exclusivamente a chuva como agente deflagrador. No segundo grupo, os eventos pluviométricos que ficaram posicionados acima do limiar pluviométrico crítico global proposto por Kanji et al 
Tabela 2. Registros de escorregamentos e eventos pluviométricos associados

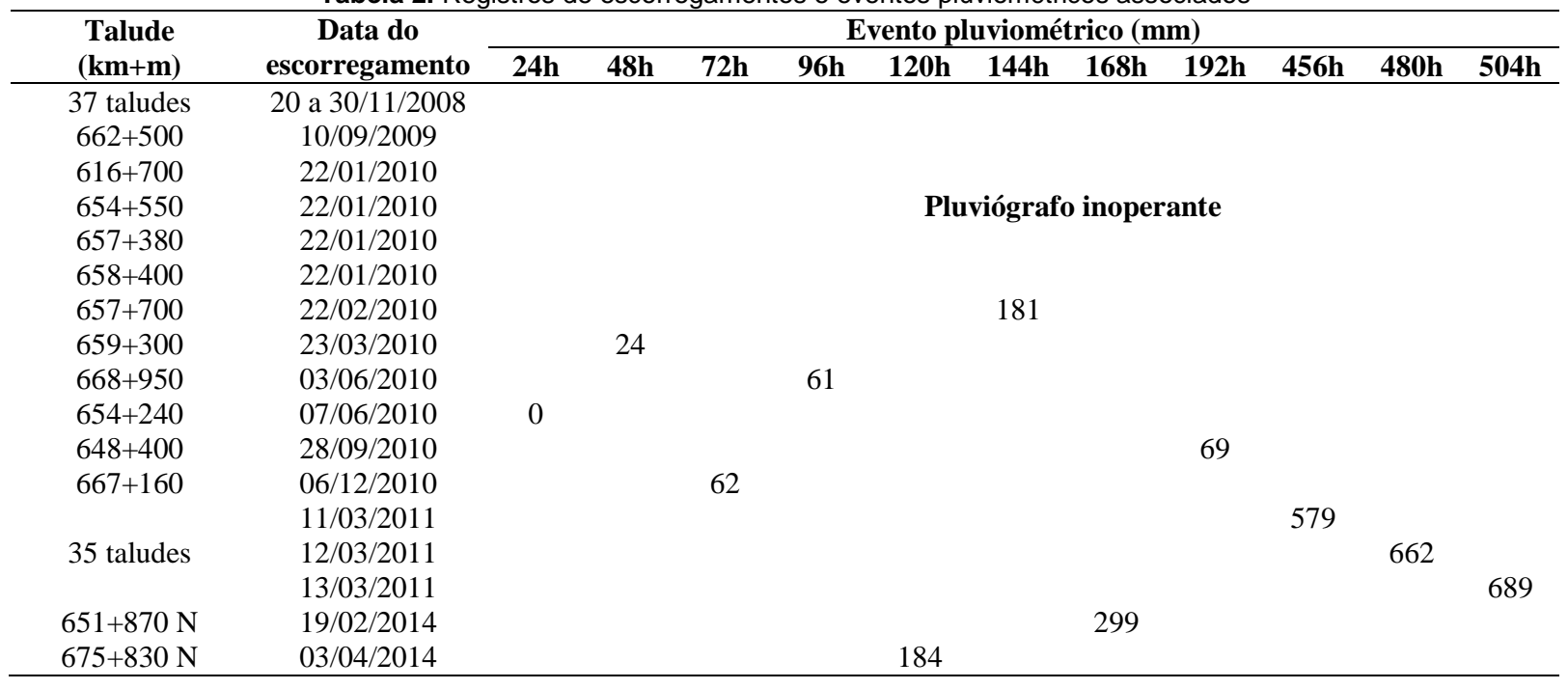

(1997) foram individualmente avaliados e, quando aplicável, excluídos ou reposicionados para o primeiro grupo de dados. Os critérios adotados para exclusão ou reposicionamento dos dados amostrais estão individualmente descritos no item 3.3 .

A Tabela 2 apresenta o local $(\mathrm{km})$ onde foram registrados escorregamentos com as respectivas datas e eventos pluviométricos associados.

\subsection{Diagrama de correlação entre chuva e escorrega- mentos}

Para a elaboração do diagrama de correlação entre as chuvas e escorregamentos foram utilizadas planilhas eletrônicas. Os dois grupos de eventos pluviométricos e o limiar pluviométrico crítico proposto por Kanji et al. (1997) foram sobrepostos em diagramas que relacionam a chuva acumulada em milímetros e o tempo em horas. Com base nessas informações, buscou-se ajustar uma região a partir da qual predomina a ocorrência de movimentos de terra, definindo assim uma faixa crítica de precipitação para a região.

A Figura 4 apresenta tanto os eventos classificados no primeiro grupo de dados (associados a escorregamentos) como no segundo (não associados), incluindo-se também a curva que define o limiar pluviométrico global empírico proposto por Kanji et al. (1997), dada pela Equação 01.

Os escorregamentos registrados entre 20 de novembro de 2008 e 22 de janeiro de 2010 foram excluídos do estudo visto que a estação pluviométrica de Itararé estava inoperante nas respectivas ocasiões. Em complemento a isso, foi possível verificar que, com exceção dos deslizamentos ocorridos em 11, 12 e 13 de março de 2011, o volume de chuva acumulado nos 30 dias anteriores à ocorrência dos escorregamentos registrados foi inferior a $350 \mathrm{~mm}$ (Figura 5). Tal valor corresponde a uma ordem de grandeza com ocorrência frequente na série histórica, sugerindo pouca influência da chuva acumulada nos 30 dias antecedentes nos escorregamentos.

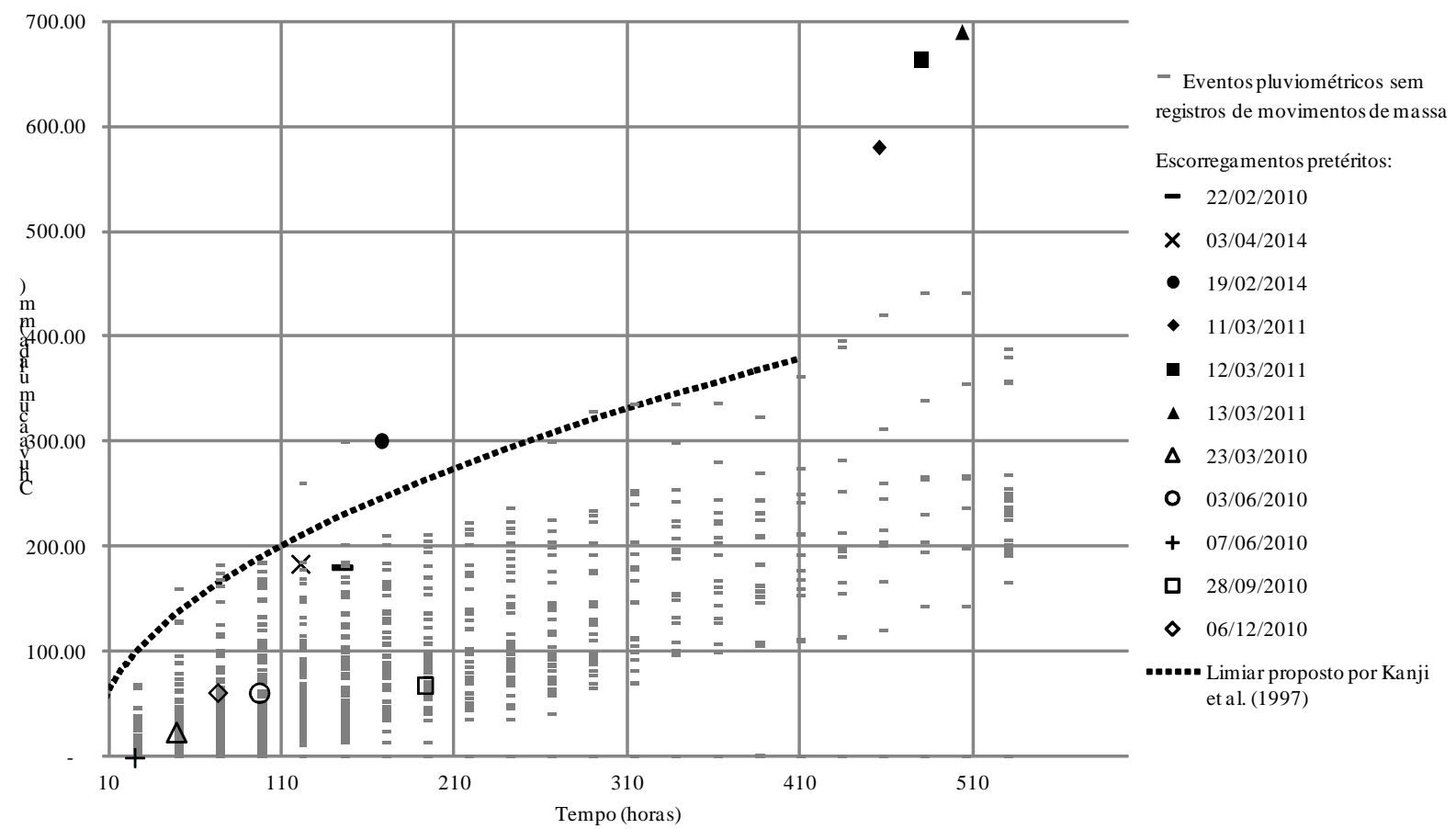

Figura 4. Eventos pluviométricos registrados pela estação Itararé e limiar pluviométrico global proposto por Kanji et al. (1997) - Em destaque os eventos que deflagraram escorregamentos 


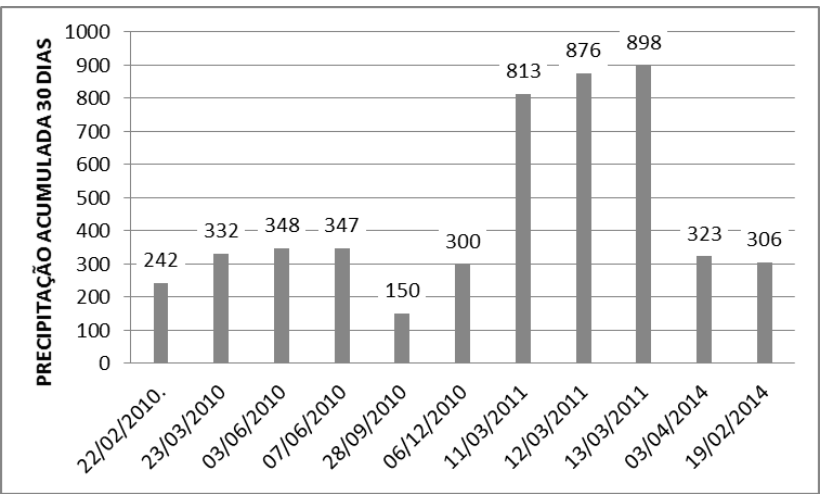

Figura 5. Precipitação acumulada durante 30 dias antecedentes a cada ruptura

Cabe salientar que existem outros fatores que influenciam a estabilidade de uma encosta, mesmo quando o principal agente deflagrador é a precipitação, tais como: condições geoestruturais, litológicas, topográficas e hidrogeológicas (e.g. D'ORSI, 2011; OLIVEIRA, 2012; SESTREM et al., 2013 e KANJI et al.,1997).

Com base na proposição acima e visto que os eventos pluviométricos e os acumulados mensais associados e antecedentes aos escorregamentos registrados em 23/03/2010, 03/06/2010, 07/06/2010, 28/09/2010 e 06/12/2010 não possuem um volume de chuva atípico, inferiu-se que a instabilidade dos taludes em questão não foi deflagrada exclusivamente pela ação da chuva. Ou, ainda, as chuvas registradas pela estação podem não ter sido de fato as que deflagaram tais rupturas. Assim, optou-se por remover essas ocorrências da análise.

O escorregamento registrado em 22/02/2010 no km 657+700m está associado a um evento pluviométrico de $181,20 \mathrm{~mm}$ durante 144 horas. Comparando essa chuva com a média de chuva histórica pode-se observar que tal evento pluviométrico é de fato atípico e mesmo abaixo do limite crítico proposto por Kanji pode-se inferir que o escorregamento pode ter sido de fato deflagrado pela chuva registrada.
Analisando-se o grupo de eventos pluviométricos sem registro de movimentos de massa, pode-se observar (Figura 4) que 06 ocorrências que supostamente não deflagraram escorregamentos estão acima do limite crítico proposto por Kanji et al (1997). Para os eventos com $181 \mathrm{~mm}$ acumulados durante 72 horas em 01/08/2011 e com $174 \mathrm{~mm}$ acumulados em 72 horas em 19/02/2010 não foram registrados escorregamentos, mas o volume precipitado foi considerado alto quando comparado com a série histórica. Além disso, os eventos pluviométricos de 17/02/2014 ( $259 \mathrm{~mm}$ em 120 horas) e 18/02/2014 (299 mm em 144 horas) foram associados à ruptura registrada em 19/02/2014 e, portanto, excluídos das análises.

Os eventos acumulados em 72 horas no dia 11/03/2006 e em 48 horas em 10/03/2006 foram registrados em período prévio ao início da concessão da rodovia, quando não existia cadastro de eventuais rupturas. Como o volume acumulado nesses dois episódios foi alto em relação à média da série histórica e com base nas incertezas associadas à ausência de registros de escorregamentos neste período, definiu-se por classificá-los dentro do primeiro grupo de dados (eventos de chuvas associados a escorregamentos). Esses dois eventos pluviométricos foram considerados como eventos críticos.

A Figura 6 apresenta o limiar pluviométrico crítico definido para área de estudo, tendo-se incluído também o limiar proposto por Kanji et al (1997) para efeito de comparação.

O limite inferior da faixa define chuvas críticas para deflagração de escorregamentos na área de estudo mais conservadoras enquanto o limite superior da faixa um limiar pluviométrico para deflagração de escorregamentos mais arrojado, ou seja, volumes de chuva localizados acima do limite inferior da faixa pluviométrica já podem ser adotados para um processo de alerta aos usuários da rodovia para o risco de escorregamentos de terra.

O limite inferior da faixa pluviométrica crítica para deflagração de movimentos de massa proposta é definido pela Equação (02) e o limite superior pela Equação (03).
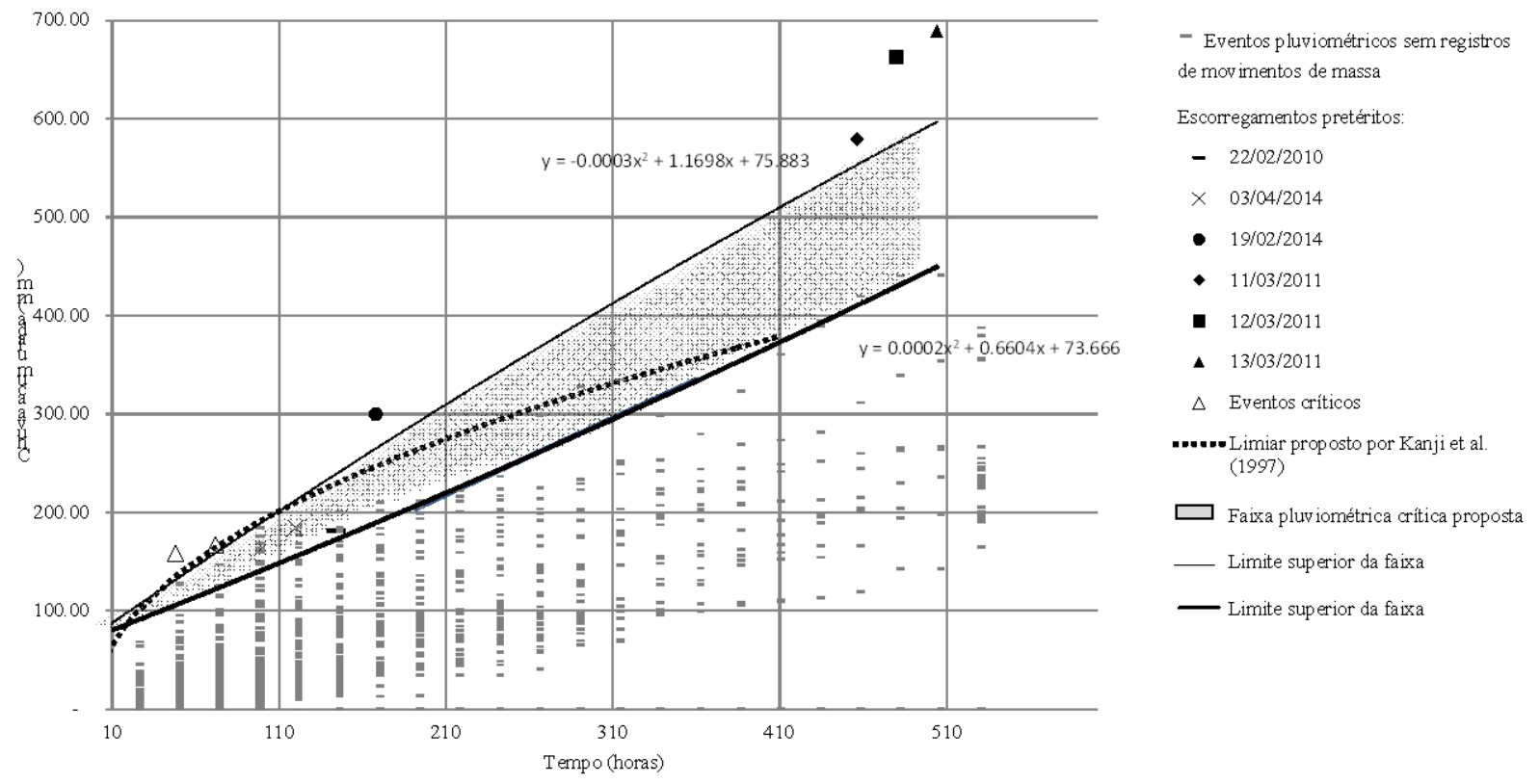

Figura 6. Faixa pluviométrica para deflagração de escorregamentos proposto para a área de estudo definida após o tratamento dos dados de chuva e escorregamento disponíveis 

do Mar da Rodovia BR-376/PR

$$
\begin{aligned}
& y=0.0002 x^{2}+0.6604 x+73.666 \\
& y=-0.0003 x^{2}+1.1698 x+75.883
\end{aligned}
$$

\section{CONCLUSÕES E CONSIDERAÇÕES FINAIS}

A correlação entre escorregamentos pretéritos e eventos pluviométricos reais para o trecho da Serra do Mar paranaense entre os quilômetros 648 e 682 da BR-376 possibilitou a delimitação de uma faixa que estabelece volumes de chuva para ocorrência de escorregamentos no local.

A distância entre o pluviógrafo e os pontos de escorregamento foi um limitador no processo de elaboração da faixa pluviométrica crítica e resultou na exclusão de casos de escorregamentos reais da série histórica. Em contrapartida, é importante ressaltar que apesar do limiar proposto ter sido construído com base em poucos registros de escorregamentos, o mesmo foi respaldado por um grande número de eventos de chuva que não deflagraram movimentos de massa na região. Tais dados sustentam a metodologia desenvolvida e validam sua aplicação.

Para trabalhos futuros sugere-se a instalação de um número maior de pluviógrafos ao longo da rodovia e a calibração dos limites da faixa pluviométrica crítica propostos neste trabalho com vistas a definição de um limiar, ou seja, de uma única linha que limite o volume de chuva acumulado para o qual escorregamentos possam ocorrer no local.

Com base no conjunto de informações disponíveis, a relação entre pluviometria e ocorrência de escorregamentos proposta representa uma ferramenta para criação sistemas de alerta e desenvolvimento de um plano de mitigação de movimentos de terra para o local. Sua aplicação torna-se ainda mais eficiente se associada a uma rede mais densa de estações pluviométricas capazes de processar dados em tempo real, possibilitando assim a emissão de alertas com o objetivo de se tomar decisões em termos de mobilização de equipes, interrupção ou desvio preventivo do tráfego ou controle de velocidade.

Este trabalho limitou-se a definição de uma faixa de volumes de chuva mínima para deflagração de movimentos de terra baseada em dados empíricos de escorregamentos e chuvas de uma dada região e nenhuma análise de condições de estabilidade dos específicos taludes foi considerada.

Sugere-se uma avaliação complementar da condição de estabilidade das encostas existentes ao longo da rodovia com base na caracterização geológica-geotécnica, declividade, topografia, tipo de cobertura (vegetação), entre outras, visando deste modo a avaliação da influência da chuva nas condições de segurança das especificas encostas.

\section{AGRADECIMENTOS}

Os autores agradecem à ANTT - Agência Nacional de Transportes Terrestres, à Autopista Litoral Sul - Grupo Arteris pelo apoio à pesquisa e viabilização deste estudo e à CAPES pelo apoio financeiro e concessão de bolsas.

\section{REFERÊNCIAS}

Calvetti, L.; Beneti, C. A. A; Pereira Filho, E. A. J. (2003) Características das estimativas de precipitação por radar, satélite e pluviômetros no Paraná: uma comparação entre chuva de verão e chuva provocada por frente fria. Anais XV Simpósio brasileiro de recursos hídricos, Curitiba, CD-ROM.

D’Orsi, R. N. (2011) Correlação entre pluviometria e escorregamentos no trecho da Serra dos órgãos da rodovia federal BR-116 RJ (Rio - Teresópolis). Tese de doutorado em Ciências e Engenharia Civil na Universidade Federal do Rio de Janeiro, COPPE, Rio de Janeiro, 287 p.

Fiori, A. P. (2014) VI Relatório Interno de Pesquisa. Recursos para Desenvolvimento Tecnológico. Projeto 04, Curitiba. 52 p.

Guzzetti F.; Peruccacci, S.; Rossi, M.; Stark, C.P. (2007) Rainfall thresholds for the initiation of landslides. In central and southern Europe. Meteorology and Atmospheric Physics, v. 98, p. 239267. DOI:10.1007/s00703-007-0262-7.

INPE - INSTITUTO NACIONAL DE PESQUISAS ESPACIAIS. (2013). Disponível em <http://www.inpe.br/> acesso em julho, 2013.

ITCF - Instituto de Terras e Cartografia. Reservas Estaduais. Relatório de Situação, Curitiba: ITCF, 1977.

Kanji, M. A.; Cruz, P. T.; Massad, F.; Araujo, F. H. A. (1997) Basic and Common Characteristics of Debris Flows. Anais do 2nd Pan Am. Symposium, 2nd COBRAE, 1997, Rio de Janeiro, v. 10 , p. $223-231$.

Kormann, A. C. M. ; Fiori, A. P.; Sestrem, L. P.; Victorino, M. M. (2013) Riscos geológico-geotécnicos em taludes rodoviários: desenvolvimento de uma metodologia de mapeamento e gerenciamento integrado de informações para a BR-376, trecho da Serra do Mar (PR-SC). Anais do VIII Workshop de Recursos de Desenvolvimento Tecnológico nas Concessões Rodoviárias: Soluções Técnicas e Aplicadas, 2013, Brasília. v. Único. p. 1323.

Mezzomo, S. M.; Araújo F. A. I.; Asakawa, S. (2012) Ações emergenciais adotadas nos acidentes geotécnicos ocorridos na BR376/PR em março de 2011. Anais do XVI Congresso Brasileiro de Mecânica dos Solos e Engenharia Geotécnica, ABGE, Porto de Galinhas.

Mieres, L. S.; Rosa, A. F. M.; Saldanha, C. B.; Alves, R. C. M.; Saldanha R. L. (2011) Avaliação de fontes alternativas de dados de precipitação para aplicação em modelos hidrológicos. Anais do XV Simpósio Brasileiro de Sensoriamento Remoto, INPE, Curitiba, p. 5300-5307.

Oliveira, G.A. (2012) Correlação entre Pluviometria, Piezometria e Movimentos das Encostas dos Quilômetros 87 e 101 da Rodovia BR 116/RJ (Rio-Teresópolis). Tese de doutorado em Ciências e Engenharia Civil na Universidade Federal do Rio de Janeiro, COPPE, Rio de Janeiro.

Peruccacci S.; Brunetti, M. T.; Luciani, S.; Vennari, C.; Guzzetti, F. (2012) Lithological and seasonal control on rainfall thresholds for the possible initiation of landslides in central Italy. Geomorphology, v. 139-140, p. 79-90. DOI:10.1016/j.geomorph.2011.10.005.

Saito, H.; Nakayama, D.; Matsuyama H. (2010) Relationship between the initiation of a shallow landslide and rainfall intensity - duration thresholds in Japan. Geomorphology, v. 118, p. 167-175. DOI:10.1016/j.geomorph.2009.12.016.

Sestrem, L. P.; Kormann, A. C. M. (2013) Implantação de um sistema de monitoramento automatizado para monitoramento de uma encosta litorânea rodoviária. Anais do $8^{\circ}$ Congresso Brasileiro de Rodovias e Concessões, Santos, Brasil. 
Tatizana, C.; Ogura, A. T.; Cerri, L. E. S.; Rocha, M. C. M.

(1987a) Análise de Correlação entre Chuvas e Escorregamentos

- Serra do Mar, Município de Cubatão. Anais do $5^{\circ}$ Congresso

Brasileiro de Geologia de Engenharia, v. 2, pp. 225-236, ABGE, São Paulo (SP), Brasil.

Tatizana, C.; Ogura, A. T.; Cerri, L. E. S.; Rocha, M. C. M.

(1987b) Modelamento numérico da análise de correlação entre

Chuvas e Escorregamentos aplicado às encostas da Serra do Mar.

Anais do $5^{\circ}$ Congresso Brasileiro de Geologia de Engenharia, v.

2, pp. 237-248, ABGE, São Paulo (SP), Brasil.

Tucci, C. E. M. (1993) Hidrologia: Ciência e Aplicação (2a ed.). Editora UFRGS, ABRH, 952p.

Victorino, M. M. (2015). Influência da chuva nas poropressões e estabilidade dos taludes rodoviários de um trecho da BR 376 na Serra do Mar paranaense. Dissertação - Universidade Federal do Paraná, Setor de Tecnologia, Programa de Pós-graduação em Engenharia de Construção Civil,

Victorino, M. M.; Sestrem, L. P.; Kormann, A. C. M.; Benetti, L. (2015) Planejamento, Implantação e Operação de Uma Rede De Pluviógrafos Na Serra Do Mar Paranaense. Anais do $15^{\circ}$

Congresso Brasileiro de Geologia de Engenharia e Ambiental, Bento Gonçalves-RS, Brasil.

Wolle, M. C.; Hachich, W. (1989) Rain-induced landslides in southeastern Brazil. Anais do 12th Int. Conf. on Soil Mech. and Found. Eng., Rio de Janeiro, p. 1639-1642.

Yuan C. C.; Chien, C. T.; Chieh, Y. F.; Hui, Y. W.; Chieh T. C. (2005) Rainfall duration and debris-flow initiated studies for real-time monitoring. Environ Geol, v. 47, p. 715-724.

DOI:10.1007/s00254-004-1203-0. 